\title{
The potential role of scar mapping in assessing of paroxysmal atrial fibrillation recurrence after cryoballoon application
}

\author{
Tolga Aksu ${ }^{\mathrm{a}, *}$, Tumer Erdem Guler ${ }^{\mathrm{a}}$, Kivanc Yalin ${ }^{\mathrm{b}}$, Kazım Serhan Ozcan ${ }^{\mathrm{a}}$ \\ a Kocaeli Derince Education and Research Hospital, Department of Cardiology, Kocaeli, Turkey \\ b Bayrampasa Kolan Hospital, Department of Cardiology, Istanbul, Turkey
}

\section{A R T I C L E I N F O}

\section{Article history:}

Received 6 May 2016

Received in revised form 7 June 2016

Accepted 10 June 2016

Available online 25 June 2016

\section{Keywords:}

Atrial fibrillation

Mapping

Ablation

Cryoballoon

Radiofrequency

\begin{abstract}
A B S T R A C T
Cryoballoon ablation for atrial fibrillation (AF) has become a frequently used therapy after failure of at least one antiarrhythmic drug. The main target of AF ablation has been durable pulmonary vein isolation. However, it is unclear if ablation strategies need to be modified after recurrence. Herein, we presented a female patient undergoing successful pulmonary vein re-connection ablation after left atrial scar mapping. In electroanatomical mapping, gray area shows intense scar tissue. Gray, red, and purple areas indicate atrial potentials $<0.5 \mathrm{mV}, 0.5-$ $1.5 \mathrm{mV}$, and $>1.5 \mathrm{mV}$, respectively. Please note that there is a non-scar area in the bottom of right inferior pulmonary vein (arrow).

(C) 2016 The Society of Cardiovascular Academy. Production and hosting by Elsevier B.V. All rights reserved. This is an open access article under the CC BY-NC-ND license (http://creativecommons.org/licenses/by-nc-nd/4.0/).
\end{abstract}

\section{Introduction}

At this time, pulmonary vein isolation (PVI) is the recommended treatment for patients with drug-resistant paroxysmal atrial fibrillation (PAF). Cryoballoon ablation may be used as an alternative to radiofrequency (RF) ablation with similar success rates in patients with PAF. In nearly all cases in which AF recurs after PVI, 1 or more of the pulmonary veins (PVs) is found to have re-established electrical connection to the atria. ${ }^{1-3}$ Gaps in the line of ablations ${ }^{4}$ or failure to produce completely transmural lesions ${ }^{5}$ are thought to be the main responsible mechanism of PV reconnection. If the actual mechanism of electrical reconnection is understood, it may increase to ratio of more durable PVI or may cause modification of current ablation approach. To discuss possible mechanisms of PV reconnection, we presented a female patient in whom left atrial scar mapping was performed to define cause of PV re-connection.

\section{Case}

A 64 year old female patient had undergone PVI with cryoballoon in our center 14 months ago. The patient was being followed as part of a research project. The patient was asymptomatic and Holter monitoring

\footnotetext{
* Corresponding author at: Kocaeli Derince Education and Research Hospital, Department of Cardiology, Ibni Sina Mah, Derince, Kocaeli, Turkey. Tel.: +90 5319903278; fax: + 902623178000 .

E-mail address: aksutolga@gmail.com (T. Aksu).

Peer review under responsibility of The Society of Cardiovascular Academy.
}

showed no new episode during 1, 3, 6 and 12 months follow-up visits. During previous cryoballoon application, $\mathrm{PV}$ potentials had been detected in each of the 4 pulmonary veins and isolated successfully. She admitted to our emergency department with haemodynamically intolerable palpitation two weeks ago. Atrial fibrillation with high ventricular response was detected on her admission ECG. Restoration of sinus rhythm was achieved by electrical cardioversion with $150 \mathrm{~J}$ biphasic shock. Due to previous ablation procedure, we decided to perform new procedure to define and treat the arrhythmia. Transthoracic echocardiography showed that left atrial diameter is $4.5 \mathrm{~cm}$ and left ventricular $\mathrm{EF}$ is $55 \%$. To determine recurrence probability of new ablation procedure, we decided to define left atrial scar by using Ensite Velocity scar mapping system. The atrial potentials which are smaller than $0.5 \mathrm{mV}$ accepted as intense scar on sinus rhythm. As expected, wide antral scar area was detected due to previous cryoapplication (Figs. 1 and 2). However, there was only one region demonstrating atrial potentials greater than $1 \mathrm{mV}$ in the bottom of right inferior PV (Figs. 1 and 2). Not surprisingly, intracardiac recordings showed re-connection only in this region. Intense scar tissue was not detected in the rest of the left atrium and the other 3 pulmonary vein still seems isolated. So, we decided to perform RF ablation in only that site. After ablation and at 3 months follow-up, no further tachycardia was noted.

\section{Discussion}

In the present case, we used scar mapping feature of electroanatomical mapping system to define the actual cause of recurrence. It has been known over longer time periods that there are some possible 


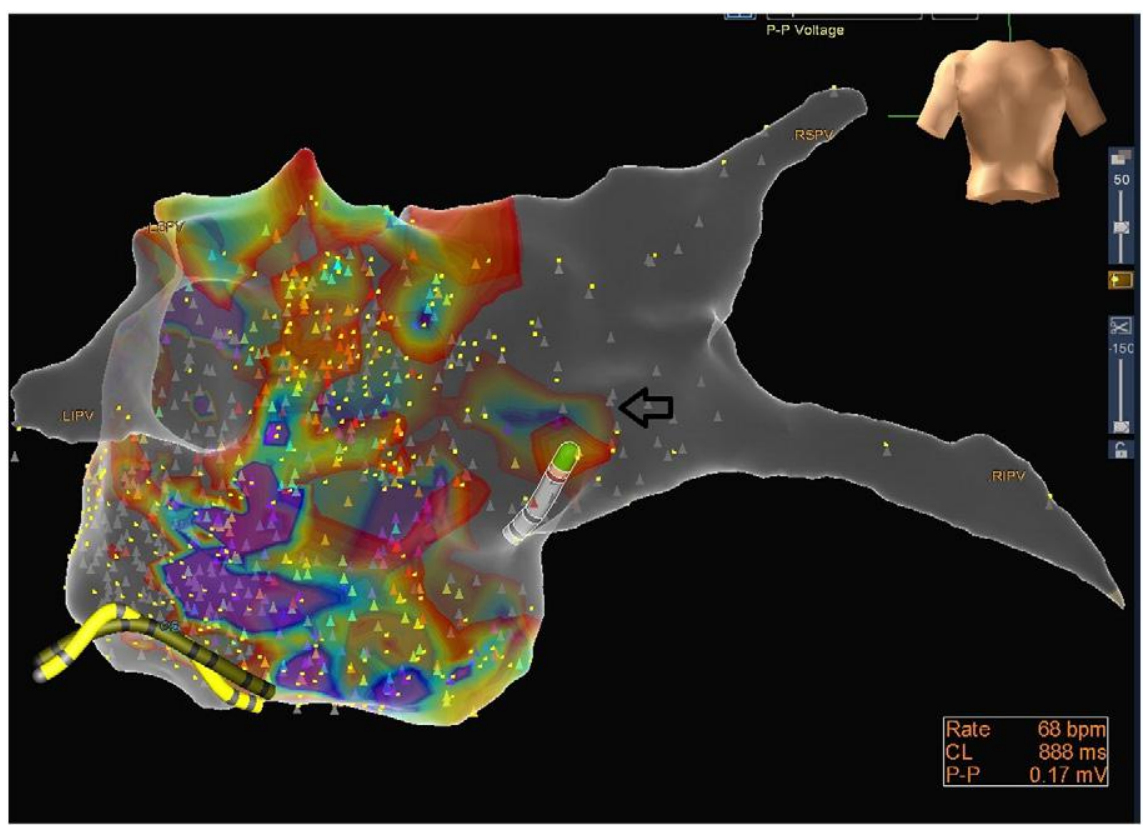

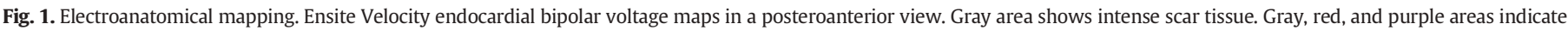
atrial potentials $<0.5 \mathrm{mV}, 0.5-1.5 \mathrm{mV}$, and $>1.5 \mathrm{mV}$, respectively. Please note that there is a non-scar area in the bottom of right inferior pulmonary vein (arrow).

mechanisms related with reconnection of PV conduction. Kowalski et al. ${ }^{6}$ demonstrated that scar tissue due to PVI may exhibit nuclear pyknosis and myocytolysis after the index ablation, suggesting that some of left atrial tissue may remain viable and capable of recovery over a prolonged period of time. However, recurrence of AF may occur despite of durable PVI. As a potential explanation, recurrent AF might be triggered and maintained by tissue outside the PVs in these patients. ${ }^{7,8}$ Surprisingly, reconnection of PVs may be seen even in patients without recurrent AF. So, clinical importance of reconnection remains uncertain.

It is well known that consistent PVI can be obtained if transmural and contiguous lesions are achieved. To indicate transmural damage, late gadolinium enhancement with magnetic resonance imaging may be used which can identify transmural level of scar tissue ${ }^{5}$ even also distinguish scar from edema. ${ }^{9}$ Although there are some contradictory thoughts, Kowalski et al. $^{6}$ have provided objective pathological evidence supporting the hypothesis that PV reconnection may be caused by a failure to achieve a transmural lesion despite acute evidence for isolation.

In our case, we detected healthy tissue in the bottom of right inferior PV. When we investigated this site for PV potentials, we defined PV reconnection. So, we speculated that the main reason of PV re-connection may be non-transmural nature of previous ablation lesion. The evaluation of scar tissue by using electroanatomical mapping systems may show main responsible mechanism whether PV reconnection or ineffective lesion. In the relevant literature, scar mapping was used as a tool to assess overall extension of left atrial scarring. However, in our case, we used scar mapping to demonstrate nature and cause of gap in PV ablation line. This may be an important difference from previous studies.

For today, independently whether AF paroxysmal or persistent, quantity of left atrial scar tissue may determine clinical success rate of ablation procedure. Therefore, the determination of scar quantity by

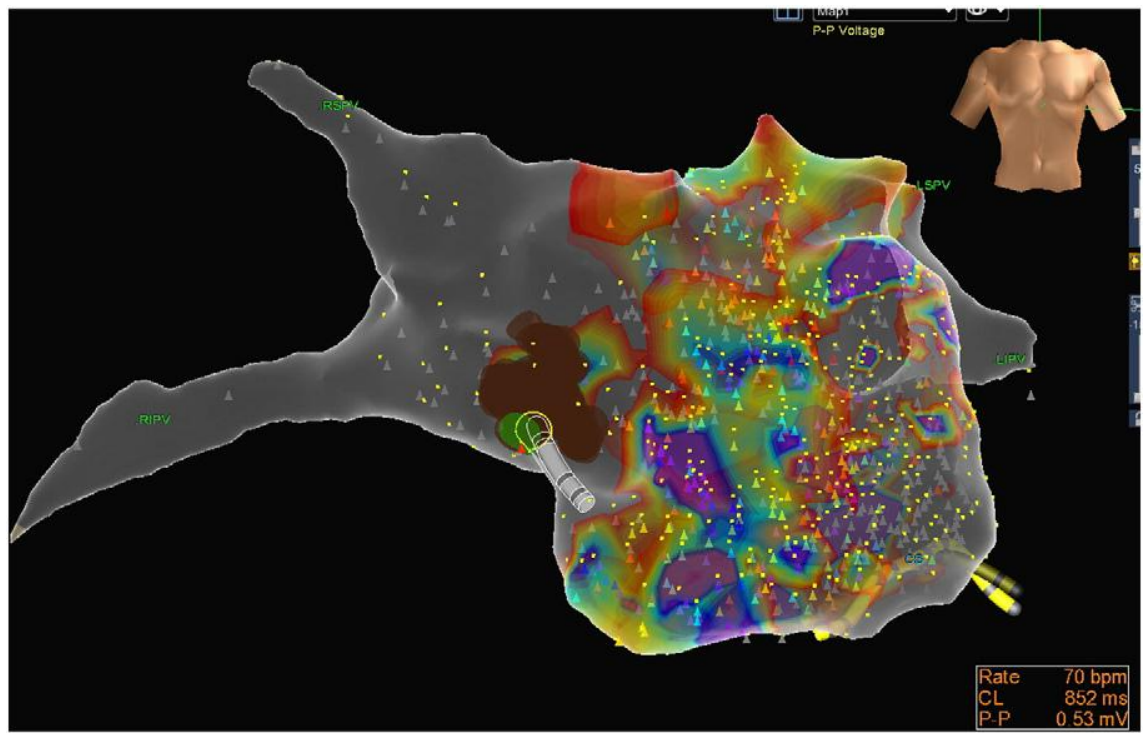

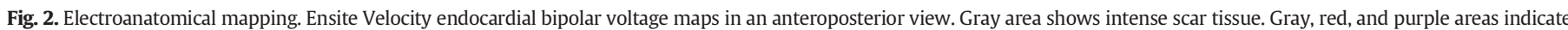
atrial potentials $<0.5 \mathrm{mV}, 0.5-1.5 \mathrm{mV}$, and $>1.5 \mathrm{mV}$, respectively. Brown spheres indicate radiofrequency ablation lesions. 
using scar mapping or magnetic resonance imaging must be kept in mind especially in patients presenting with recurrence after cryoballoon application.

\section{References}

1. Callans DJ, Gerstenfeld EP, Dixit S, et al. Efficacy of repeat pulmonary vein isolation procedures in patients with recurrent atrial fibrillation. J Cardiovasc Electrophysiol 2004; 15:1050-1055.

2. Cappato R, Negroni S, Pecora D, et al. Prospective assessment of late conduction recurrence across radiofrequency lesions producing electrical disconnection at the pulmonary vein ostium in patients with atrial fibrillation. Circulation 2003;108:1599-1604

3. Nanthakumar K, Plumb VJ, Epstein AE, Veenhuyzen GD, Link D, Kay GN. Resumption of electrical conduction in previously isolated pulmonary veins: rationale for a different strategy? Circulation 2004;109:1226-1229.
4. Ranjan R, Kato R, Zviman MM, et al. Gaps in the ablation line as a potential cause of recovery from electrical isolation and their visualization using MRI. Circ Arrhythm Electrophysiol 2011;4:279-286.

5. McGann CJ, Kholmovski EG, Oakes RS, et al. New magnetic resonance imaging-based method for defining the extent of left atrial wall injury after the ablation of atrial fibrillation. J Am Coll Cardiol 2008;52:1263-1271.

6. Kowalski M, Grimes MM, Perez FJ, et al. Histopathologic characterization of chronic radiofrequency ablation lesions for pulmonary vein isolation. J Am Coll Cardiol 2012;59: 930-938.

7. Ouyang F, Bansch D, Ernst S, et al. Complete isolation of left atrium surrounding the pulmonary veins: new insights from the double-Lasso technique in paroxysmal atrial fibrillation. Circulation 2004;110:2090-2096.

8. Verma A, Kilicaslan F, Pisano E, et al. Response of atrial fibrillation to pulmonary vein antrum isolation is directly related to resumption and delay of pulmonary vein conduction. Circulation 2005;112:627-635.

9. Dickfeld T, Kato R, Zviman M, et al. Characterization of radio-frequency ablation lesions with gadolinium-enhanced cardiovascular magnetic resonance imaging. J Am Coll Cardiol 2006:47:370-378. 